\title{
Nonoperative management of large tracheal injuries
}

\author{
Chadrick E. Denlinger, MD, Nirmal Veeramachaneni, MD, Alexander S. Krupnick, MD, G. Alexander Patterson, MD, \\ and Daniel Kreisel, MD, PhD, St Louis, Mo
}

Supplemental material is available online.

$\mathrm{T}$ racheobronchial injuries occur rarely as the result of trauma or iatrogenically from airway intubation. Classic surgical teaching mandates prompt diagnosis and surgical repair. More recently, however, support for nonoperative management of tracheal injuries in selected patients has been established. We present 2 cases of large iatrogenic tracheal injuries managed successfully without operative intervention and with excellent clinical outcomes.

\section{Clinical Summary}

CASE 1. A 29-year-old woman was strangulated and subsequently rescued by the emergency medical service, who performed orotracheal intubation at the scene. On evaluation in the emergency department she was found to have a pneumomediastinum, and an aerodigestive tract injury was suspected. A membranous $5-\mathrm{cm}$ tracheal laceration was identified by bronchoscopy that extended from the mid-trachea to the orifice of the left mainstem bronchus (Figure 1, A). Nonoperative management was chosen because the patient had no clinical evidence of mediastinitis and a chest computed tomography scan did not demonstrate any significant mediastinal fluid collection. After 9 days of observation and intravenously administered antibiotics, she was discharged without ongoing manifestations of the tracheal injury. A follow-up bronchoscopy 6 weeks later showed complete tracheal healing with minimal granulation tissue present (Figure 1,B).

CASE 2. A 76-year-old woman was noted to have cervical pain, dysphagia, and significant subcutaneous emphysema after an elective laparoscopic cholecystectomy with orotracheal intubation. She remained afebrile and clinically stable during transportation from the referring hospital. A computed tomography scan with 3-dimensional reconstructions confirmed the presence of a membranous trachea injury extending $5 \mathrm{~cm}$, from the mid-trachea to the carina, with no significant mediastinal fluid collections but marked medias-

From the Department of Cardiothoracic Surgery, Barnes-Jewish Hospital, Washington University, St Louis, Mo.

Received for publication Sept 20, 2007; accepted for publication Dec 7, 2007.

Address for reprints: Daniel Kreisel, MD, PhD, Division of Cardiothoracic Surgery, Campus Box 8234, 660 South Euclid Avenue, St Louis, MO 63110-1013 (E-mail: kreiseld@wudosis.wustl.edu).

J Thorac Cardiovasc Surg 2008;136:782-3

0022-5223/\$34.00

Copyright $\odot 2008$ by The American Association for Thoracic Surgery doi:10.1016/j.jtcvs.2007.12.040 tinal emphysema (Figure 2, $A$ and $B$; Figure E1, $A$ ). On the basis of the patient's clinical stability with no signs of mediastinitis, as well a noticeable reduction in subcutaneous emphysema, a nonoperative approach was selected. She was treated with antibiotics and observed for 9 days before discharge. A follow-up bronchoscopy 2 months later demonstrated complete healing of the tracheal injury without evidence of stricture or granulation tissue (Figure E1, $B$ ).

\section{Discussion}

The larger published series of tracheal injuries indicate that approximately $50 \%$ of all tracheal injuries are iatrogenic. Typically, the membranous portion of the trachea is injured and occurs with an incidence of 1 in 20,000 intubations with single-lumen tubes and $0.5 \%$ to $1.0 \%$ of intubations with double-lumen tubes. ${ }^{1}$ Contemporary case series have supported nonoperative management for patients with small membranous tracheal lacerations provided they remain clinically stable. Ross and colleagues ${ }^{2}$ proposed the following criteria to define clinical stability conducive to nonoperative treatment: stable vital signs, no difficulty with ventilator (if intubated) or freedom from respiratory distress if intubated, no concomitant esophageal injury, minimal mediastinal fluid, no signs of sepsis, and no progression of subcutaneous or mediastinal air. Subsequent reports and the cases presented here support these selection criteria. ${ }^{1-3}$

Nonoperative management has been most strongly advocated for lacerations less than 2 to $4 \mathrm{~cm}$ in length. ${ }^{1,3}$ Surgical repair, however, has been recommended for patients sustaining larger tracheal lacerations, in part, because they are more likely to have associated signs of clinical instability. ${ }^{1,4}$ The cases presented in this report suggest that even extensive tracheal lacerations can also be managed successfully nonoperatively provided the patient remains clinically stable. Membranous tracheal lacerations of $5 \mathrm{~cm}$ in length were successfully managed in each patient with antibiotics and observation alone without any short- or long-term complications.

Involvement of the cartilaginous trachea or circumferential tracheal injuries, typically the result of blunt trauma, are unlikely to be successfully managed without surgery. Although a cartilaginous injury does not strictly exclude conservative management, experience suggests that these patients are less likely to meet criteria for nonoperative therapy. ${ }^{5}$ To date, there are no reports of cartilaginous injuries occurring iatrogenically as the result of orotracheal intubation.

Airway strictures and granulation tissue formation remain a significant long-term concern for patients sustaining tracheal injuries. Reports of patients managed nonoperatively do not suggest that they require laser treatments, airway resections, endobronchial stents, or other treatments for strictures. ${ }^{5}$ However, strictures caused by granulation tissue forming at the site of tracheal repair have been reported. ${ }^{5}$ Therefore, nonoperative treatment is acceptable in the presence of clinical stability, and this approach may be preferable to minimize long-term complications and the requirement for granulation tissue debridement. 

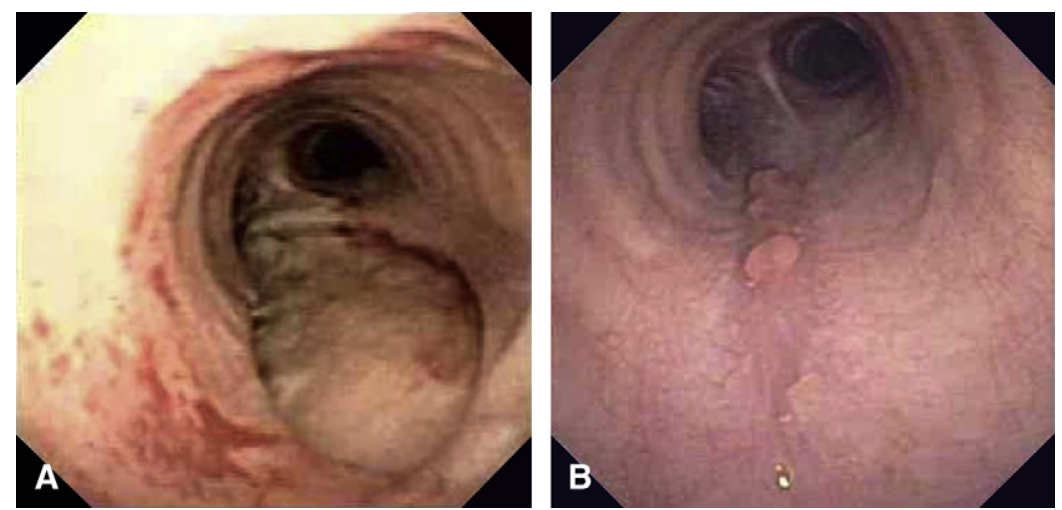

Figure 1. Bronchoscopic image of trachea and carina at the time of injury $(A)$ and 6 weeks after injury (B).
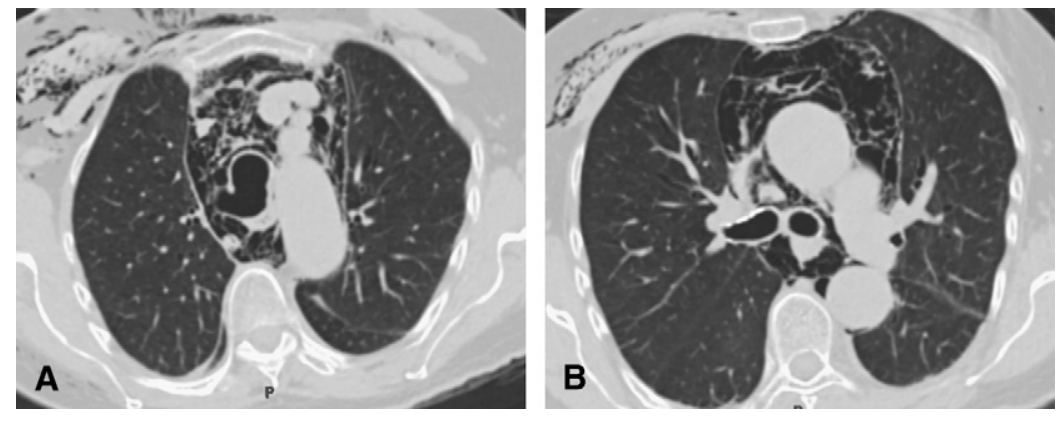

Figure 2. Axial computed tomography images at the time of injury showing membranous tracheal injury with marked mediastinal emphysema (A and $B$ ).

\section{Conclusions}

We report 2 cases of patients with extensive membranous tracheal injury managed nonoperatively. The length of the membranous tracheal injury does not mandate surgical repair if the patient remains clinically stable without evidence of worsening subcutaneous emphysema or mediastinitis.

\section{References}

1. Carbognani P, Bobbio A, Cattelani L, Internullo E, Caporale D, Rusca M. Management of postintubation membranous tracheal rupture. Ann Thorac Surg. 2004;77:406-9.
2. Ross HM, Grant FJ, Wilson RS, Burt ME. Nonoperative management of tracheal laceration during endotracheal intubation. Ann Thorac Surg. 1997;63:240-2.

3. Andres AG, Moradiellos FJ, Herrero PA, Gude VD, Cabrero EL, Porch EM, et al. Successful conservative management in iatrogenic tracheobronchial injury. Ann Thorac Surg. 2005;79:1872-8.

4. Hofmann HS, Rettig G, Radke J, Neef H, Silber RE. Iatrogenic ruptures of the tracheobronchial tree. Eur J Cardiothorac Surg. 2002;21: $649-52$.

5. Gomez-Caro A, Austin P, Moradiellos FJ, Diaz-Hellin V, Larru E, Perez JA, et al. Role of conservative medical management of tracheobronchial injuries. J Trauma. 2006;61:1426-35. 

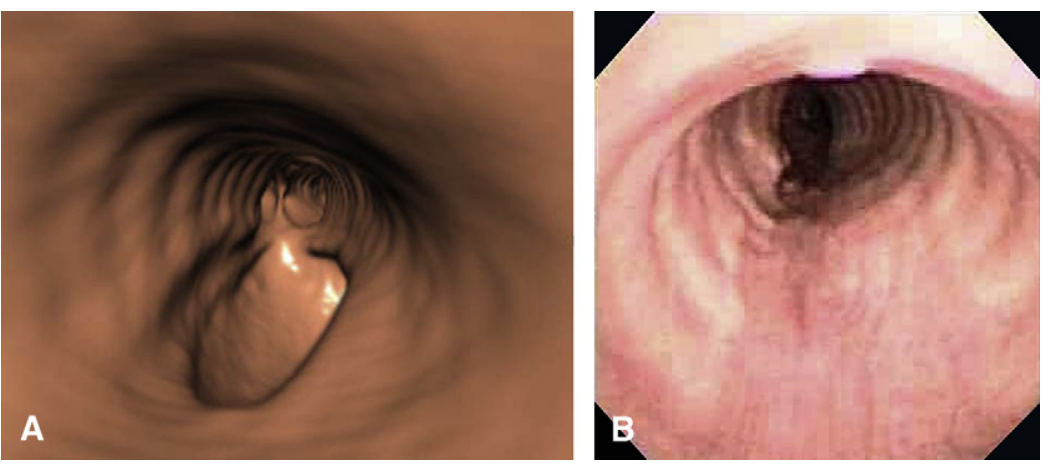

Figure E1. Computed tomography 3-dimensional reconstruction of tracheal injury $(A)$ and bronchoscopic view 8 weeks after injury showing complete closure of trachea (B). 